\title{
A VISÃO HISTÓRICA DA IN(EX)CLUSÃO DOS SURDOS NAS ESCOLAS
}

\section{Karin Lílian Strobel}

"A educação integrada pesa por ser depredatória da identidade surda.. A educação do surdo tem de ser a educação específica com códigos da cultura surda".

GLÁDIS PERLIN

\section{RESUMO}

A história do povo surdo mostra que por muitos séculos de existência, a pedagogia, as políticas e muitos outros aspectos próprios têm sido elaborados sempre sob uma perspectiva dos ouvintes e não dos surdos que, quase sempre, são ignorados e desvalorizados como sujeitos e profissionais que podem contribuir a partir de suas capacidades inerentes e de sua diferença: a de ser surdo. Desta maneira, a 'inclusão' de sujeitos surdos nas escolas, tendo-se a língua portuguesa como principal forma de comunicação, faz-nos questionar se a inclusão significa integrar o surdo realmente. Na verdade, a palavra correta para as experiências desenvolvidas não é 'inclusão', e sim uma forçada 'adaptação' com a situação do dia-a dia dentro de sala de aula.

\section{PALAVRAS-CHAVE}

Educação de surdos; História surda; Inclusão/exclusão

\section{A HISTORY APPROACH ABOUT THE UN(EX)CLUSION OF DEAF PEOPLE IN SCHOOLS}

\begin{abstract}
The History of the deaf people shows that for many centuries of existence, the pedagogy, the politics and many other proper aspects have been elaborated always under a perspective of the listeners and not of the deaf people, who almost always are ignored, devaluated while citizens and professionals who can contribute from its inherent capacities and of its difference: of the deaf being. In this way, inclusion` of the deaf citizens in the schools, having itself Portuguese language as main form of communication in makes them to rethink well if the inclusion means to integrate the deaf person? In the truth the correct word is not inclusion`, and yes one forced adaptation with the situation of the day-by-day inside the classroom.
\end{abstract}

\section{KEY WORDS}

Deaf education; Deaf history; Inclusion/exclusion

(C) ETD - Educação Temática Digital, Campinas, v.7, n.2, p.245-254, jun. 2006 - ISSN: 1676-2592. 


\section{DOSSIÊ \\ Grupo de Estudos e Subjetividade}

Para compreender o porquê do que propomos hoje na busca de uma educação diferente ao povo surdo ${ }^{1}$, do que pensávamos ser o melhor há muitos anos atrás, das profundas transformações do processo de desenvolvimento da educação dos surdos, é essencial resgatar um pouco dos vestígios históricos que marcaram o contexto da ‘inclusão’ dos surdos no cenário educacional brasileiro, que por sua vez foi influenciado pelas tendências pedagógicas fora do país.

Entretanto, com a inclusão dos surdos no processo educacional, vimos que esses sujeitos não desenvolveram o seu potencial em virtude do historicismo ${ }^{2}$, ou seja, o poder dos ouvintes que queriam que os sujeitos surdos se adaptassem ao modelo ouvintista ${ }^{3}$, impondo-lhes o oralismo e o treinamento auditivo, não respeitando a identidade cultural dos mesmos. Porém, a difusão da língua de sinais e de sua identidade cultural permitiu aos sujeitos surdos os meios de desenvolvimento de seu potencial.

A educação inclusiva é um fato imposto em muitos países, inclusive no Brasil; entretanto, historicamente, veremos que tem havido fracasso na educação de surdos. Por que este fracasso escolar? Apesar dos nossos esforços em educar os sujeitos surdos durante muitos séculos de atendimento e reabilitação de fala, ocorreu um desequilíbrio, gerado pela não escolarização efetiva dos mesmos.

Neste ínterim, como começou a inclusão de surdos nas escolas regulares? Com a Declaração de Salamanca ${ }^{4}$ (BRASIL, 1997) decorre a política educacional ‘inclusiva’ que, na verdade, trouxe para os sujeitos surdos a inversão da vida comunicativa: incluir para excluir do processo educacional.

A política evidenciada na Declaração de Salamanca foi adotada na maioria dos países e inspirou a elaboração da Lei de Diretrizes e Bases da Educação (BRASIL, 1996). Todavia se, na LDB, em um de seus capítulos sobre a educação especial, há a ênfase e a inclusão de parâmetros para a integração/inclusão do aluno especial na escola regular - na Declaração de Salamanca (BRASIL, 1997) há a menção à situação lingüística dos surdos e se defende as escolas e classes para eles (artigo 21, p.

\footnotetext{
${ }^{1}$ Povo Surdo: Conjunto de sujeitos surdos que não habitam o mesmo local, mas que estão ligados por uma origem, tais como a cultura surda, usam a língua de sinais, têm costumes e interesses semelhantes, histórias e tradições comuns e qualquer outro laço compartilhado. ( STROBEL, 2006. p.6)

${ }^{2}$ Historicismo: doutrina segundo a qual cada período da história tem crenças e valores únicos; devendo cada fenômeno ser entendido através do seu contexto histórico; Disponível em <(http://www.priberam.pt/dlpo/definir_resultados.aspx)> Acesso em 10/02/2005. Em Estudos Surdos, a definição de Historicismo é a história concebida na visão do ouvintismo.

3 Ouvintismo, segundo SKLIAR, "é um conjunto de representações dos ouvintes, a partir do qual o surdo está obrigado a olhar-se e narrar-se como se fosse ouvinte”. (1998a, p 15).

${ }^{4}$ A Declaração de Salamanca foi resultado das várias declarações das Nações Unidas que culminaram no documento intitulado "Regras Padrões sobre Equalização de Oportunidades para Pessoas com Deficiências", o qual demanda que os Estados assegurem que a educação de pessoas com deficiências seja parte integrante do sistema educacional.
}

(C) ETD - Educação Temática Digital, Campinas, v.7, n.2, p.245-254, jun. 2006 - ISSN: 1676-2592. 


\section{DOSSIÊ \\ Grupo de Estudos e Subjetividade}

30). O problema é que os governos não respeitaram essa ressalva e trataram os surdos como os demais alunos.

Então, os alunos surdos (que antes que eram excluídos) estão agora sendo destituídos do direito de sua língua, na inclusão em escolas de ouvintes. Mas isto está sendo feito corretamente? Isto é o ideal? Realmente significa a ‘inclusão’ para os surdos?

Apesar da proposta inclusiva ser uma coisa maravilhosa 'no papel', ainda estamos bem distantes do que realmente seria a inclusão.

A realidade brasileira é uma coisa deprimente, pois sabemos que a proposta governamental é colocar o sujeito surdo na sala de aula com professores sem capacitação para trabalhar com surdos. Vemos muitos sujeitos surdos concluírem o Ensino Médio sem saber escrever sequer um bilhete.

Ao percorrer a trajetória histórica do povo surdo e suas diferentes representações sociais, procuramos impetrar a compreensão do porquê de muitos sujeitos surdos sofrerem os fracassos da inclusão, nas escolas de ouvintes.

Em toda a história da humanidade os estereótipos que se referem ao povo surdo demonstram o domínio do ouvintismo, relativo a qualquer situação relacionada à vida social e educacional dos sujeitos surdos. Embora não sejam poucos estes registros de dominação, frente ao povo surdo, vemos que historicamente o povo ouvinte sempre decidiu como seria a educação de surdos.

Neste sentido, vamos refletir estes momentos históricos da exclusão, integração e inclusão por que passava a educação de surdos no mundo.

Assim, na antiguidade, os sujeitos surdos eram estereotipados como 'anormais', com algum tipo de atraso de inteligência, devido à ausência de trabalho e pesquisas científicas desenvolvidos na área educacional. Para a sociedade, o 'normal' era que: é preciso falar e ouvir para ser aceito, então os sujeitos surdos eram excluídos da vida social e educacional; não havia escolas para os sujeitos surdos e existiam muitas leis que não acreditavam na capacidade de surdos, assim como cita Quirós (1966, p.154):

(...) ao final da data antiga, falávamos em textos jurídicos de opinião sigilosa, também equiparando entre surdos e dementes, nada disso nos devia nos assombrar, por isso muitas legislações que não estavam em vigência, apresentavam os mesmos erros conceituais.

Na Roma antiga, os romanos herdaram dos Gregos a idolatração pela perfeição física. Assim, os recém nascidos que apresentavam imperfeições físicas eram sacrificados. No entanto, este destino não

(C) ETD - Educação Temática Digital, Campinas, v.7, n.2, p.245-254, jun. 2006 - ISSN: 1676-2592. 
se aplicava muitas vezes aos bebês surdos, porque não se percebia a surdez ao nascerem, assim como descreve Radutzky (1992, p.11) :

Em Roma, eles eram colocados na base de uma estátua nas praças principais e então devorados pelos cães. Por este motivo muitos historiadores pensaram que certamente às crianças surdas não se desse tal destinação dado que, seguramente, mesmo hoje é muito difícil fazer um diagnóstico precoce da surdez.

Portanto, por volta de 753 a.C., o fundador da Roma, o imperador Rômulo, decretou uma lei onde todos os recém-nascidos que fossem incômodo para o Estado deveriam ser mortos até aos três anos. Então, por isso, muitos surdos não conseguiam fugir deste destino bárbaro.

Além de serem sacrificados, os sujeitos surdos eram também marginalizados do convívio social; eram isolados, eram presos em celas e calabouços, asilos e hospitais, ou feitos de escravos, assim como afirma Foucault no seu livro 'História da Loucura' desde o século XIV ao século XVII ao percorrer na história da loucura percebemos que devido aos valores éticos, morais e o modelo médico estão fortemente enraizados socialmente então a exclusão de sujeitos era e é ainda uma prática constante, isto é, a eliminação de pessoas indesejadas. (2002).

A distinção dos sujeitos surdos nem sempre foi feita entre os deficientes físicos e mentais e nem mesmo aos pobres. Os sujeitos surdos geralmente eram assimilados aos marginais, exclusos da sociedade, como objetos de compaixão ou ainda em um trabalho de esforço de conciliação cristã; então, na época, geralmente nos monastérios, os monges beneditinos inseriam os surdos em suas atividades manuais, mas em nenhuma intelectual.

Nessa fase, não havia a preocupação de formação educacional de sujeitos surdos, uma vez que os mesmos não eram vistos como cidadãos produtivos ou úteis à sociedade.

A partir de século XVI, pedagogos e filósofos apaixonados pela educação debatiam sobre a integração social dos surdos: de qual integração se tratava? Qual será o preço que o povo surdo iria pagar por esta integração?

Esta preocupação educacional de surdos deu lugar às aparições de numerosos professores que desenvolveram, simultaneamente, seus trabalhos com os sujeitos surdos e de maneira independente, em diferentes lugares da Europa. Havia professores que se abocavam na tarefa de comprovar a veracidade da aprendizagem dos sujeitos surdos ao usar a língua de sinais e o alfabeto manual e em muitos lugares havia professores surdos, como explica Lane (1992, p.36) : 
(...) quase metade dos professores eram surdos. Não existiam audiologistas, terapeutas de reabilitação, ou psicólogos educacionais e, para a maioria, nenhum destes eram aparentemente necessários. (...) pelo contrário a criança e o adulto surdos eram descritos em termos culturais: que escola freqüentaram, quem eram os seus parentes e amigos surdos (caso os houvesse), quem era a sua esposa surda, onde trabalhavam, quais as equipes desportivas de surdos e organizações de surdos a que pertenciam, qual o serviço que prestavam à comunidade dos surdos?

Após o congresso internacional ocorrido em Milão ${ }^{5}$, no ano de 1880, o uso de língua de sinais foi definitivamente banido a favor do oralismo:

Por quase um século, as línguas de sinais foram perseguidas nas mesmas instituições que supostamente deveriam propagá-las. Mas os códigos não chegaram a ser eliminados, mas simplesmente conduzidos ao mundo marginal, onde sobreviveram graças às contraculturas estabelecidas pelas crianças nas escolas, clandestinas , rebeldes e cruéis. (RÉE , acessado em 24/07/2005)

Durante cem anos, os sujeitos surdos ficaram subjugados às práticas ouvintistas, tendo que abandonar sua cultura e sua identidade surda, obrigados a se submeterem a uma 'etnocentria ouvintista', sendo forçados a imitá-los e a se esforçarem em parecer ouvintes. A educação de surdos no Brasil foi influenciada pelas metodologias que surgiram nos séculos XVI a XIX.

Com a evolução dos estudos de medicina sobre a surdez, as ciências da vida começaram a categorizar os sujeitos surdos, segundo suas representações, em graus de surdez (os surdos leves de um lado, e os profundos em outro extremo); desse modo, os surdos passaram a ser considerados 'doentes' e 'deficientes'. O fato de os sujeitos surdos terem dificuldade para ouvir e falar é que reforçou esta representação.

Nessa fase, no século XIX, o atendimento era voltado à filantropia e ao assistencialismo; os sujeitos surdos eram entregues pelas famílias às instituições e asilos, em regime de internato até que estivessem aptos para retornar para o convívio familiar, o que, invariavelmente acontecia no início da idade adulta.

No século XX, entra em cena a preocupação de resgatar os surdos do anonimato e trazê-los ao convívio social, como sujeitos com direitos que mereceriam a atenção de todas as instituições

\footnotetext{
${ }^{5}$ Em 1880, foi realizado um Congresso Internacional de Milão, Itália, para discutir o futuro da educação para os surdos e para avaliar o mérito de três métodos rivais: língua de sinais, oralista e mista (língua de sinais e a fala).No dia 11 de setembro de 1880, houve uma votação de 160 votos com quatro contra, a favor de métodos orais na educação de surdos.
}

(C) ETD - Educação Temática Digital, Campinas, v.7, n.2, p.245-254, jun. 2006 - ISSN: 1676-2592. 
educacionais organizadas e, assim, ocorreu a expansão do atendimento especializado, com as campanhas de prevenção e identificação da surdez.

Deste modo, o ouvintismo ganhou legitimidade pelos discursos científicos, em especial, da Medicina, da Logopedia e das áreas clínicas em geral, em pleno florescimento no século XX. Torna-se mais refinado o poder ouvintista sobre os surdos e houve avanços na visão clínica, que faziam das escolas dos surdos espaços de reabilitação de fala e treinamento auditivo, preocupando-se apenas em 'curar' os surdos que eram vistos como 'deficientes' e não em educar.

Muitos sujeitos surdos foram triados, avaliados e encaminhados a classes especiais em escolas públicas em cidades do interior, e, nas capitais, foi estimulada a criação de instituições de reabilitação particulares. Desta fase, até uns vinte anos atrás, a educação de surdos caracterizou-se pelo predomínio de modelos clínicos, nos quais, em detrimento dos objetivos educacionais, estavam em prioridade os objetivo de reabilitação.

Persistiu a aplicação de inúmeros métodos oralistas, geralmente estrangeiros, buscando estratégias de ensino que poderiam transformar em realidade o desejo de ver os sujeitos surdos falando e ouvindo, fazendo com que os órgãos governamentais dessem enormes verbas para a aquisição de equipamentos que pudessem potencializar os restos auditivos. Do mesmo modo, houve projetos de formação de professores leigos que muitas vezes faziam o papel de fonoaudiólogos, ficando assim a proposta educacional direcionada somente para a reabilitação de fala aos sujeitos surdos.

Com isto, houve o fracasso educacional dos sujeitos surdos, uma vez que este discurso sobre a educação dos mesmos estava fora do contexto, pois muitas vezes os sujeitos surdos eram vistos como 'retardados', sendo poupados dos conteúdos escolares mais complexos, 'empurrados' de uma série para outra, e também foram proibidos de compartilhar uma língua cultural do povo surdo, sendo tratados como débeis mentais, com a eternização da infância.

Hoje o Brasil conta com várias classes especiais, salas de recursos, ou seja, espaços educacionais para surdos dentro de escolas regulares para garantir o atendimento de alunos surdos matriculados nas diferentes escolas brasileiras e também escolas para surdos,

Hoje o povo surdo identifica-se como 'surdo', que forma um grupo com as características lingüísticas específicas, cognitivas e culturais, sendo considerados como diferença!

Fernandes (1998, p.21) descreve o comovente momento do povo surdo, na sua dissertação de mestrado: 
(...) resistindo às pressões da concepção etnocêntrica dos ouvintes, organizou-se em todo o mundo e levantou bandeiras em defesa de uma língua e cultura próprias, voltando a protagonizar sua história. A principio, as mudanças iniciais vêm sendo percebidas no espaço educacional, através de alternativas metodológicas que transformam em realidade o direito do surdo a ser educado em sua língua natural.

Na concepção educacional atual, a inclusão dos sujeitos surdos em escolas de ouvintes é a forma mais rápida e certa de voltar a chamar o sujeito surdo de 'deficiente', porque o que está sendo feito atualmente é apenas um jogo político em que um governo quer “deixar uma vírgula a mais” nas leis de governos passados.

Muitos pedagogos, psicólogos e até doutores e mestres alimentam os discursos de inclusão lingüística e cultural dos surdos, sem perceber as conseqüências deste processo que só tem contribuído mais ainda para o fracasso educacional dos sujeitos surdos. Estes especialistas não têm nenhuma experiência na prática em sala de aula com os sujeitos surdos, acabando por colocar os referidos sujeito no mesmo patamar dos deficientes visuais, deficientes mentais e outros, sem se dar conta que os sujeitos surdos possuem uma identidade lingüística e cultural que os diferencia dos outros. Segundo Skliar (1998, p.37):

Um dos problemas, na minha opinião, é a confusão que se faz entre democracia e tratamento igualitário. Quando um surdo é tratado da mesma maneira que um ouvinte, ele fica em desvantagem. A democracia implicaria, então, no respeito às peculiaridades de cada aluno seu ritmo de aprendizagem e necessidades particulares.

São pouquíssimos os professores habilitados para trabalhar com os sujeitos surdos. Nas faculdades de Pedagogia, por exemplo, há especializações para uma ou outra área de deficiência. Optam por uma e excluem outras. Ou terão que torná-las todas obrigatórias? Assim como relata uma surda, estudante de pedagogia:

Uma vez na faculdade, durante muitos anos no curso de pedagogia sempre discutiram muito sobre a importância de inclusão de surdos nas escolas regulares, etc. Em uma ocasião, a professora psicóloga fez uma atividade que consistia que cada um dos alunos dizer a qualidade da pessoa escolhida e presentearia com um bombom e assim por diante. No final de tudo, já presenteados seus colegas escolhidos, nos sobraram duas surdas, a intérprete e a minha mãe, $a$ ultima colega ouvinte escolheu a interprete para presentear e ela sem graça, sem saber qual de nos duas escolheria para presentear e disse, que escolheria nos duas juntas, a professora impediu-a dizendo que não pode e teria que escolher uma, então a interprete chateada 


\section{DOSSIÊ \\ Grupo de Estudos e Subjetividade}

presenteou a minha mãe com um bombom. A minha mãe, na vez dela levantou, vendo a nossa mágoa e caras de choramingo e disse a professora e a todos os colegas de pedagogia: isto se chama a inclusão? Vocês demonstraram na pratica que "excluíram” as duas surdas! ${ }^{6}$

Em outras palavras, quem está perdendo com isso tudo são os sujeitos surdos, pois há a ruptura de uma cultura surda. .

Isto nos faz repensar bem se a inclusão social oferecida significa integrar o surdo. Na verdade, com esta situação citada anteriormente a palavra correta não é 'inclusão', e sim uma forçada ‘adaptação’ com a situação do dia-a dia dentro de sala de aula.

Como uma criança surda poderá desenvolver uma língua se não houver uma identificação com o surdo adulto? Como o sujeito surdo poderá fazer uma identificação com relação à sua identidade surda no futuro, se ele não conviver com outros surdos que façam uso da língua de sinais? Quem foi que disse que é só o sujeito surdo utilizar-se da língua de sinais que por um "passe de mágica” ele passará a ter uma aprendizagem total? E a cultura como fica?

O sujeito surdo deve ter a possibilidade de estudar em escola de surdos e lutar por espaços onde possa comunicar-se e ser entendido adequadamente; entretanto, a realidade é que existe no Brasil o total de 5.564 municípios e é ofertado atendimento de educação especial a 82,3\% destes municípios ${ }^{7}$. O que fazer com os sujeitos surdos que moram em cidades pequenas, onde não existe comunidade surda? Como vamos tirá-los de perto de suas famílias e mandá-los para as instituições nas grandes cidades? Isto não é voltar na história ? .

Nestes casos, o ideal sobre a inclusão nas escolas de ouvintes, é que as mesmas se preparem para dar aos alunos surdos os conteúdos pela língua de sinais, através de recursos visuais, tais como figuras, língua portuguesa escrita e leitura, a fim de desenvolver nos alunos a memória visual e o hábito de leitura; que recebam apoio de professor especialista conhecedor de língua de sinais e enfim, proporcionando intérpretes de língua de sinais, para o maior acompanhamento das aulas. Outra possibilidade é contar com a ajuda de professores, instrutores e monitores surdos, que auxiliem o professor e trabalhem com a língua de sinais nas escolas. Cito novamente Skliar (1998, p.37):

\footnotetext{
${ }^{6}$ Agradeço a Rosani Suzin em permitir que o seu relato humanizasse o trabalho.

${ }^{7}$ Fonte: http://portal.mec.gov.br/seesp/index.php?option=content\&task=view\&id=62\&Itemid=191).

(C) ETD - Educação Temática Digital, Campinas, v.7, n.2, p.245-254, jun. 2006 - ISSN: 1676-2592. 
Nesse sentido, a escola democrática é aquela que se prepara para atender cada um de seus alunos. Se ela não tem condições de fazer esse atendimento, o professor precisa entrar em contato com os órgãos competentes e discutir o tema. Como responsável por vários cursos de libras e de interpretes, entendo que a formação de professores para atender a alunos surdos depende da convivência com a comunidade surda, a aprendizagem da língua de sinais e o estudo de uma pedagogia ampla.

E os municípios menores poderão organizar atividades pólos sistematicamente, já que os sujeitos surdos necessitam interagir entre si para que a língua de sinais esteja em evolução e os usuários tenham fluência lingüística.

O Brasil precisa perceber o sujeito surdo, como uma diferença lingüística e cultural. Como é que os governantes brasileiros e parte da sociedade defendem a inclusão de tantos grupos marginalizados como uma forma de transformação social, se sequer conseguem notar as diferenças de quem está concretamente ao seu lado, sem ser notado? 


\section{REFERÊNCIAS:}

BRASIL. Ministério da Justiça. Secretaria Naiconal dos Direitos Humanos. Declaração de Salamanca e linha de ação. Brasília: CORDE, 1997.

BRASIL. Diretrizes e Bases da Educação Nacional - LEI 9394-96. Brasília: Congresso Nacional. DOU 23/12/96. Acessível no site <http://www.mp.pe.gov.br/procuradoria/caops/caop_infancia/Lei_9394_96.htm>. Acessado em 04/05/2006.

FERNANDES, S. F. Surdez e Linguagem: é possível o diálogo entre as diferenças? Dissertação ( mestrado em ....)- Faculdade de ... UFSC, Curitiba, 1998.

FOUCAULT, M. História da Loucura. São Paulo: Editora Perspectiva, 2002.

LANE, H. A Máscara da Benevolência: a comunidade surda amordaçada. Lisboa: Instituto Piaget, 1992.

QUIRÓS, J. B. ; GUELER, F.S. . La Comunicacíon humana y su patología: Ensayo histórico hasta 1900. Buenos Aires, Argentina: Casa Ares, 1966.

STROBEL, K. L. Projeto de mestrado Surdos: Vestígios Culturais não registrados na Historia, Florianópolis, UFSC, 2006.

SKLIAR, C. A forma visual de entender o mundo. In Educação para todos . Revista especial, SEED/DEE. Curitiba: Editora Expediente, 1998

RADUTZKY, E. . Dizionario bilíngüe elementare della língua italiana dei segni. Roma, Itália: Edizioni Kappa, 1992.

RÉE, J. Os deficientes auditivos são uma nação a parte? Inglaterra, 2005. Disponível em:< http://noticias.uol.com.br/midiaglobal/prospect/2005/03/ult2678.jhtm>. Acessado em: 24/07/2005. 